\title{
POLA PENDIDIKAN KARAKTER SISWA SMK BERBASIS PESANTREN
}

\author{
Syukri Fathudin Achmad Widodo ${ }^{1}$, Wahidin Abbas ${ }^{2}$ \\ 1,2 Jurusan Pendidikan Teknik Mesin FT UNY \\ Email: syukri@uny.ac.id
}

\begin{abstract}
The purpose of this research are: 1) to determine the concept of character education pattern in SMK Syubbanul Wathon, and 2) to determine factors affecting Character Education Pattern of SMK Syubbanul Wathon students. The research is a descriptive research with a qualitative approach. The research was carried out in SMK Syubbanul Wathon Pondok Pesantren API Tegalrejo in the Magelang district. Data were collected using participative observations, thorough interviews, and documentation. Data validation were ensured by maintaining credibility, transferability, dependability and conformability. Result shows that the school's character education pattern is based on akhlakul karimah which main traits are autonomy and modesty. It becomes the character and soul of students (santri) in their social life. The boarding school integrates Salafi teaching, with a more modernized facility and management. Factors affecting the education pattern are students' social background and their behavior outside the boarding school.
\end{abstract}

Keywords: character education, education pattern, boarding school vocation education, salafi

\begin{abstract}
ABSTRAK
Tujuan penelitian ini adalah untuk 1) mengetahui gambaran pola pendidikan karakter siswa SMK dan, 2) mengetahui faktor apa saja yang mempengaruhi Pola Pendidikan Karakter siswa SMK Syubbanul Wathon. Penelitian ini merupakan penelitian deskriptif dengan pendekatan kualitatif. Penelitian dilaksanakan di SMK Syubbanul Wathon Pondok Pesantren API Tegalrejo Kab.Magelang. Teknik pengumpulan data yang digunakan adalah pengamatan partisipatif, wawancara mendalam, pengumpulan dokumen. Keabsahan data dilakukan dengan cara menjaga kredibilitas, transferabilitas, depandebilitas, dan konfirmabilitas. Hasil penelitian menunjukkan bahwa pola pembinaan karakter siswa SMK Subbanul Wathon berbasis pada akhlakul karimah yang berciri pada kemandirian dan kesederhanaan. Hal tersebut menjadi watak, jiwa siswa (santri) SMK Subbanul Wathon, dalam mengarungi kehidupan masyarakat. Integrasi pendidikan ala pondok pesantren Salaf, fasilitas dan manajemen yang cukup modern. Sedangkan faktor-faktor yang mempengaruhi pola pembinaan siswa SMK Subbanul Wathon diantaranya: latar belakang sosial siswa dan kebiasaan-kebiasaan siswa saat berada di luar lingkungan pondok.
\end{abstract}

Kata kunci: pendidikan karakter, SMK berbasis pesantren

\section{PENDAHULUAN}

Undang-Undang Sistem Pendidikan Nasional Nomor 20 Tahun 2003, Pasal 3 menyatakan bahwa Pendidikan Nasional berfungsi mengembangkan kemampuan dan membentuk watak serta peradaban bangsa yang bermartabat dalam rangka mencerdaskan kehidupan bangsa, dan bertujuan berkembang potensi peserta didik agar menjadi manusia yang beriman dan bertakwa pada Tuhan Yang Maha Esa, berakhlak mulia, sehat, berilmu, cakap, kreatif, mandiri, dan menjadi warga negara yang demokratis serta bertanggung jawab.

Pemerintah telah menetapkan Peraturan Pemerintah Nomor 19 Tahun 2005 tentang Standar Nasional Pendidikan (SNP) yang berfungsi sebagai dasar dalam perencanaan, pelaksanaan, dan pengawasan pendidikan nasional yang bermutu. SNP merupakan kriteria minimal untuk menjamin mutu pendidikan nasional dalam rangka mencerdasarkan kehidupan bangsa dan membentuk watak serta karakter bangsa yang bermartabat. Karakter manusia pada hakikatnya kodrat yang dapat 
dibentuk. Banyak faktor yang dapat menentukan pembentukan karakter manusia diantaranya adalah keluarga, sekolah dan masyarakat.

Sekolah berkontribusi dalam upaya pembentukan karakter peserta didik. Berbagai hal yang menyebabkan merosotnya nilai-nilai moral dan karakter siswa di antaranya belum adanya peraturan yang mengatur proses integrasi nilai-nilai karakter bagi siswa, kurangnya pemahaman guru tentang mengintegrasikan nilai karakter dan moral ke dalam pembelajaran, belum optimalnya peran warga sekolah dalam impelementasi pendidkan karakter dan kurangnya media pembelajaran yang mendukung pelaksanaan proses pembelajaran berbasis pendidikan karakter demikian hasil penelitian Tutuk Ningsih (2015: 10).

SMK Syubbanul Wathon adalah sebuah lembaga pendidikan kejuruan di lingkungan Pesantren Salafiyyah A.P.I Tegalrejo Magelang yang bergerak di bidang IT (Information Technology) dan dikelola oleh Yayasan Syubbanul Wathon. SMK berbasis pesantren yang terletak di kaki Gunung Merapi ini merupakan sebuah wujud kepedulian pesantren A P I Tegalrejo terhadap pentingnya pengembangan keilmuan yang mengedepankan akhlaqul karimah.

Keilmuan pesantren dan pengetahuan umum diperlukan untuk keberlangsungan kehidupan manusia. Pemetaan dan pemisahan antara keilmuan pesantren dan pengetahuan umum dalam kehidupan saat ini hanya akan menjadikan kebuntuan pengembangan keilmuan Islam. Kebutuhan masyarakat saat ini adalah hadirnya lembaga formal unggulan yang mencetak teknokrat yang handal dan dapat membekali anak didik dengan nilai-nilai keislaman. Generasi muda saat ini membutuhkan beragam ilmu untuk dapat membawa kemajuan bangsa dan Agama. Ilmu umum, ilmu agama dan juga ketrampilan.

Karena hal tersebut Pesantren Salafiyyah Tegalrejo melihat pentingnya sebuah lembaga formal yang unggul dalam pengetahuan umum dengan tetap menjunjung tinggi nilai-nilai kelimuan pesantren. SMK Syubbanul Wathon hadir sebagai sebuah lembaga pendidikan alternatif yang diharapkan dapat mencetak kader bangsa yang intelektual, mempunyai skill yang mapan dan menjunjung tinggi akhlaqul karimah. Semua diramu dengan pemikiran yang matang yang sesuai kebutuhan dan kemampuan siswa.

Program unggulan SMK Subbanul Wathon adalah Teknologi Informasi. Dengan satu landasan pemikiran bahwa perkembangan teknologi berkembang sangat cepat dari waktu ke waktu. Semua lini kehidupan sudah tidak dapat lepas dari teknologi. Dinamis dalam menyikapi perkembangan teknologi sangat dibutuhkan dewasa ini, karena tanpa disadari teknologi telah menjadi bagian dari kehidupan. Namun demikian banyak permasalahan terkait pola pembinaan karakter siswa, manajemen, kurikulum, sumberdaya. Berdasar berbagai permasalahan tersebut, perlu kiranya dilakukan penelitian mendalam tentang "Pola Pendidikan Karakter siswa SMK Syubbanul Wathon”. Sehingga dapat diketahui gambaran Pola Pendidikan Karakter siswa SMKSyubbanul Wathon dan faktor apa saja yang mempengaruhi Pola Pendidikan Karakter siswa SMK Syubbanul Wathon.

Terdapat berbagai rumusan dalam memaknai karakter maupun pendidikan karakter, yaitu: (a) Character is the combination of personal qualities that make each person unique. Teachers, parents, and community members help children build positive character qualities. For example, the six pillars of character are trustworthiness, respect, responsibility, fairness, caring, and citizenship. Character deals with how people think and behave related to issues such as right and wrong, justice and equity, and other areas of human conduct (www.eduscapes.com). (b) Character is attribute or a quality that defines a person. This means that you are defined by a certain set of habits, qualities or attitudes and these form the basis upon which you character is judged (www.indianchild.com). $\quad$ (c) Character education is the development of knowledge, skills, and abilities that encourage children and young adults to make informed and responsible 
choices (www.eduscapes.com). (d) Character education is the deliberate effort to help people understand, care about, and act upon core ethical values (Lickona, www.goodcharacter.com). Lebih lanjut Lickona mengemukakan: "When we think about the kind of character we want for our children, it's clear that we want them to be able to judge what is right, care deeply about what is right, and then do what they believe to be right-even in the face of pressure from without and temptation from within". (e) Character education is the development of knowledge, skills, and abilities that enable the learner to make informed and responsible choices. It involves a shared educational commitment that emphasizes the responsibilities and rewards of productive living in a global a diverse society (www.urbanext.illinois.edu). (f) Character education is an umbrella term loosely used to describe the teaching of children in a manner that will help them develop variously as moral, civic, good, mannered, behaved, non-bullying, healthy, critical, successful, traditional, compliant and/ or socially-acceptable beings (wikipedia.com). (g) Character education (CE) is everything you do that influences the character of the kids you (Elkin \& Sweet, 2004).

Dari berbagai pendapat tersebut secara sederhana dapat dirumuskan bahwa pada dasarnya karakter menyangkut kualitas diri dan keyakinan seseorang yang akan melandasi perilaku. Sedangkan pendidikan karakter adalah upaya meningkatkan pengetahuan, ketrampilan maupun sikap yang dibutuhkan agar seseorang berperilaku sesuai dengan nilai-nilai luhur, norma, etika, maupun aturan yang berlaku.

Implementasi pendidikan karakter pada siswa tidak terlepas dari aspek kurikulum, pembelajaran, dan iklim/budaya akademik. Oleh karenanya pertanyaan dasar yang harus dijawab dalam hal ini adalah: (1) bagaimana mengintegrasikan karakter dalam kurikulum, dan (2) bagaimana menciptakan strategi yang mendukung implementasi integrasi karakter dalam perkuliahan, (3) bagaimana menciptakan iklim dan budaya akademik dalam mendukung integrasi karakter dalam proses pendidikan.

Untuk membahas integrasi karakter dengan kurikulum, perlu disepakati dulu bahwa kurikulum adalah skenario pendidikan untuk mencapai tujuan pendidikan. Jika tujuan pendidikan adalah membantu peserta didik untuk mengembangkan potensinya agar mampu menghadapi problema kehidupan dan kemudian memecahkannya secara arif dan kreatif, berarti pembelajaran pada semua mata pelajaran seharusnya diorientasikan ke tujuan dan hasil belajar juga diukur berdasarkan kemampuan yang bersangkutan dalam memecahkan problem kehidupan. Pengembangan aspek-aspek karakter tersebut dapat dibarengkan dengan substansi matapelajaran atau bahkan sebagai metoda pembelajarannya.

Jika digunakan kurikulum berorientasi kompetensi maka karakter seharusnya dimasukan sebagai kompetensi dasar yang dikembangkan bersama mata pelajaran lainnya. Dengan demikian setiap mata pelajaran dituntut untuk mengembangkannya bersama kompetensi substansi mata pelajaran atau bahkan merupakan aplikasi substansi matakuliah dalam kehidupan. Para guru perlu merencanakan, melaksanakan dan mengevaluasi pembelajaran dengan memperhatikan integrasi pendidikan karakter dalam mata pelajaran yang diampunya.

Pelaksanaan integrasi karakter dalam pembelajaran dapat dilakukan dengan bermacam-macam strategi dengan melihat kondisi siswa serta lingkungan sekitarnya, oleh sebab itu pelaksanaan integrasi karakter dalam pembelajaran memiliki prinsip-prinsip umum seperti: (1) tidak mengubah sistem pendidikan yang berlaku, (2) tidak mengubah kurikulum, (3) pembelajaran menggunakan prinsip learning to know, learning to learn, learning to be, dan learning to live together, dan (4) dilaksanakan secara kontekstual sehingga terjadi pertautan antara pendidikan dan kebutuhan nyata peserta didik.

Dengan memperhatikan prinsip-prinsip tersebut integrasi karakter dalam pembelajaran dapat dilaksanakan dengan berbagai model, 
misalnya model pembelajaran dan pelatihan berbasis proyek (project based learning), pembelajaran berbasis masalah (problem based learning), pembelajaran terlibat secara langsung (hands-on learning), pembelajaran berbasis aktivitas (activities based learning), dan pembelajaran berbasis kerja (work based learning). Dengan model-model di atas memungkinkan subjek didik banyak melakukan sesuatu, bukan sekedar memahami dan mendengarkan.

\begin{tabular}{|c|c|c|}
\hline Sedikitnya & terdapat & tiga \\
\hline implementasi & karakter & yang \\
\hline
\end{tabular}
dipertimbangkan, yaitu: (1) model integratif, (2) model komplementatif, dan (3) model diskrit (terpisah). Dalam model integratif, implementasi karakter melekat dan terpadu dalam programprogram kurikuler, kurikulum yang ada, dan atau mata pelajaran yang ada. Program kurikuler atau mata kuliah yang ada hendaknya bermuatan kepada penanaman karakter. Model ini membutuhkan kesiapan dan kemampuan tinggi dari guru. Guru diharapkan untuk kreatif, penuh inisiatif, dan kaya gagasan. Guru harus pandai dan cekatan menyiasati dan menjabarkan kurikulum, mengelola pembelajaran, dan mengembangkan penilaian. Keuntungannya model ini, adalah relatif murah, tidak membutuhkan ongkos mahal, dan tidak menambah guru.

Dalam model komplementatif, implementasi karakter, ditambahkan ke dalam program pendidikan kurikuler dan struktur kurikulum yang ada; bukan dalam mata pelajaran. Pelaksanaannya dapat berupa menambahkan mata pelajaran karakter dalam struktur kurikulum. Model ini membutuhkan waktu tersendiri atau waktu tambahan, juga guru tambahan dan membutuhkan ongkos yang relatif mahal. Selain itu, penggunaan model ini dapat menambah beban tugas siswa dan guru serta membutuhkan finansial yang tidak sedikit yang dapat memberatkan pihak institusi. Meskipun demikian, model ini dapat digunakan secara optimal dan intensif untuk membentuk karakter mahasiswa.
Dalam model terpisah (diskrit), implementasi karakter disendirikan, dipisah, dan dilepas dari program-program kurikuler, atau mata kuliah. Pelaksanaannya dapat berupa pengembangan karakter yang dikemas dan disajikan secara khusus pada peserta didik. Penyajiaannya bisa terkait dengan program kurikuler atau bisa juga berbentuk program ekstrakurikuler. Model ini memerlukan persiapan yang matang, ongkos yang relatif mahal, dan kesiapan sekolah yang baik. Model ini memerlukan perencanaan yang baik agar tidak salah penerapan, namun model ini masih dapat digunakan untuk membentuk karakter peserta didik secara komprehensif dan leluasa.

Pemilihan model yang diterapkan tersebut akan sangat tergantung dari berbagai kesiapan beberapa aspek termasuk karakteristik institusi masing-masing. Melalui proses evaluasi diri, ujicoba, validasi, implementasi dan evaluasi akan didapatkan pola yang cocok untuk masingmasing institusi.

Aspek-aspek karakter, khususnya yang bersifat sikap (merupakan perwujudan kesadaran diri) banyak yang sebenarnya merupakan bagian aktivitas sehari-hari manusia. Secara teoritik aspek sikap atau ranah afektif lebih efektif jika dikembangkan melalui kebiasaan sehari-hari. Misalnya disiplin pada mahasiswa akan lebih mudah dikembangkan jika disiplin telah menjadi kebiasaan sehari-hari di kampus. Jujur, kerja keras, saling toleransi dan sebagainya akan mudah dikembangkan jika aspek-aspek tersebut sudah menjadi kebiasaan sehari-hari di kampus. Dalam konteks membentur kultur akhlak mulia (karakter) menjadi langkah yang dirasa efektif dalam upaya menumbuhkan sikap jujur, disiplin mahasiswa yang diharapkan nantinya sesuai dengan apa yang dibutuhkan oleh masyarakat.

Ary Kristiyani (2014) dalam hasil penelitiannya menjelaskan bahwa pendidikan karakter masih dipahami sebagai bagian pendidikan di lingkungan sekolah. Ragam cara pendekatan, salah satunya pembelajaran bahasa meneguhkan pendidikan karakter mampu menjadi dasar pengembangan watak dan 
kepribadian peserta didik. Sedangkan Winarno Narmoatmojo (2011) dalam hasil penelitiannya menyebut bahwa warga negara yang baik ukurannya adalah konstitusi negara bersangkutan. Sepanjang mematuhi konstitusi maka termasuk dalam kategori warga Negara yang baik, dan sebaliknya. Winarno juga menyatakan bahwa guru sebagai warga Negara dituntut memiliki karakter publik yang baik, memiliki identitas, dan menerima adanya nilainilai sosial.

\section{METODE}

Penelilitian ini merupakan penelitian deskriptif dengan pendekatan kualitatif, dilaksanakan pada Agustus-Oktober 2017, di SMK Syubbanul Wathon Pondok Pesantren API Tegalrejo Kab. Magelang. Subjek penelitian ini adalah Kepala SMK Syubbanul Wathon sebagai key informan. Informasi lanjutan melalui wawancara mendalam ditringulasi kebenaran pada Pimpinan Ponpes API, Komite Sekolah. Hasil wawancara ditringulasi dengan teknik pengumpulan data lainnya yaitu observasi partisipasi, dan dokumentasi.

Teknik pengumpulan data yang digunakan adalah pengamatan partisipatif, wawancara mendalam, pengumpulan dokumen (dokumentasi), pengumpulan data dengan bantuan alat-alat audio visual. Keabsahan data dilakukan dengan cara menjaga kredibilitas, transferabilitas, depandebilitas, dan konfirmabilitas. Kredibilitas data diperoleh dengan cara: a) memperpanjang masa pengamatan, b) pengamatan yang dilakukan secara terus menerus, c) trianggulasi, d) membicarakan dengan orang lain (peer debriefing), e) menggunakan bahan referensi, dan f) mengadakan member check.

\section{HASIL DAN PEMBAHASAN}

Pola pembinaan karakter siswa SMK Subbanul Wathon dilaksanakan dengan mengedapankan Akhlak (budi pekerti) seperti yang tradisi Pondok Pesantren API.Adapun kegiatan harian sebagai berikut :

Kegiatan Belajar Mengajar (KBM). Kegiatan KBM dimulai pukul 07.10 WIB untuk santri putra dengan melaksanakan apel pagi (Sabtu, Minggu, dan Senin) dan sholat dluha berjamaah (Selasa, Rabu, Kamis). Sedangkan untuk santri putri masuk pukul 12.25 WIB dengan melaksanakan do'a bersama di depan kelas (apel siang). Satu jam pelajaran setiap mata pelajaran adalah selama 35 menit. Istirahat selama 15 menit. Kegiatan KBM berakhir pada pukul 11.30 WIB untuk santri putra dan pukul 17.00 WIB untuk santri putri. KBM sekolah berakhir semua santri harus kembali ke asrama terkecuali yang mendapat tugas. Maksimal untuk santri putri pukul 17.15 WIB (setelah piket)

Selama kegiatan belajar mengajar berlangsung: (a) bagi santri yang terlambat datang ke sekolah wajib melapor kepada bagian kesiswaan/ petugas piket di kantor untuk mendapatkan surat keterangan dan ijin masuk, (b) Seluruh Dewan Pembimbing yang sedang melaksanakan KBM di dalam kelas tidak diperkenankan mengijinkan santri yang datang terlambat apabila tidak membawa surat ijin masuk dari petugas piket/kesiswaan, (c) Santri dilarang meninggalkan ruang kelas selama KBM berlangsung kecuali atas ijin pembimbing yang bersangkutan, (d) Bagi santri yang tidak hadir, wajib memberitahukan kepada pengurus dan membawa surat izin tertulis untuk di bawa ke SMK, (e) Santri sakit saat KBM SMK pulang ke asrama harus membawa surat keterangan dari SMK diserahkan kepengurus pondok

Larangan selama KBM berlangsung, yaitu santri dilarang: (a) Meninggalkan kelas/ pelajaran kecuali atas ijin pembimbing yang bersangkutan/petugas piket, (b) Makan dan minum didalam kelas, (c) Membuat keributan, suasana ramai, dan atau kegaduhan yang menyebabkan gangguan bagi santri lain yang sedang belajar, (d) Meninggalkan/keluar area pendidikan sebelum jam belajar usai kecuali atas ijin petugas piket, (e) Menggunakan laptop disaat pelajaran kosong tanpa ada izin dari pembimbing yang bersangkutan 
Seragam santri, kerapihan dan kebersihan. Ketentuan pemakaian seragam oleh santri adalah sebagai berikut: (a) Seragam sekolah sabtu dan ahad seragam hitam, kaos kaki putih, sepatu hitam dan khusus putrid menggunakan pet (WAJIB), (b) Seragam sekolah Senin dan Selasa seragamPutih Abu-abu, kaos kaki putih, sepatu hitam dan khusus putri menggunakan kaos dalam dan pet (WAJIB), (c) Seragam sekolah Rabu dan Kamis seragam warna hijau, sepatu dan kaos kaki bebas (sopan dan tidak berlebihan), (d) Santri yang tidak menggunakan seragam lengkap dengan alasan yang jelas tetapharus meminta surat ijin dengan ketentuan membayar denda sebesar Rp.1000.

Sedangkan ketentuan terkait kerapian dan kebersihan lingkungan, santri dilarang: (a) Menambah dan atau memakai atribut lain yang tidak sesuai dengan ketentuan sekolah, (b) Masuk kelas tanpa atribut dan seragam lengkap kecuali mendapatkan izin dari petugas piket/ kesiswaan, (c) Membuang sampah di sembarang tempat, (d) Memasukkan sampah di laci meja belajar, (e) Mencoret-coret semua fasilitas yang ada di kelas dan di lingkungan sekolah, (f) Masuk kantor tanpa berseragam lengkap, untuk putri: bersolek berlebihan (eye liner, lipstick yang mencolok, celak berwarna), menggunakan emas, memakai pacar kuku, aksesoris yang berlebihan (gelang dan bros yang berlebihan), menyemir rambut. Sedangkan untuk putra: berambut panjang atau potongan yang tidak sesuai, menyemir rambut, dan menggunakan aksesoris.

Perihal Umum. Santri dilarang: (a) Merokok, (b) Membawa senjata tajam atau peralatan yang membahayakan keselamatan, (c) Membawa segala jenis benda yang berbau pornografi dan benda lain yang tidak berkaitan dengan pendidikan dan pelajaran, (d) Merusak segala asset dan peralatan sekolah, (e) Melakukan tindakan yang dapat mencemarkan nama baik civitas akademika, (f) Memakai dan menggunakan aksesoris yang tidak sesuai dengan kepribadian sebagai seorang santri, (g) Melakukan perbuatan yang bertentangan dengan
Agama, Hukum, Kaidah, dan Norma yang berlaku, (h) Menyimpan foto lawan jenis kecuali saudara sekandung, menyimpan foto pribadi yang tidak mengenakan jilbab (putri)

Sangsi. Bagi santri yang terbukti melanggar segala ketentuan dan peraturan dia tas beserta ketentuan-ketentuan berikutnya akan diberi sanksi pelanggaran yang dilakukan berupa: sanksi fisik dan sanksi point.

Hak-hak santri. Setiap santri berhak: (a) Mendapatkan perlakuan yang sama dari seluruh Dewan Pengurus dan Dewan Pembimbing SMK Syubbanul Wathon Tegalrejo, (b) Mendapatkan pengajaran yang sama dari Dewan Pembimbing, (c) Menggunakan segala fasilitas yang dimiliki sekolah dengan memperhatikan ketentuan yang ditetapkan, (d) Mengikuti segala kegiatan yang diadakan pihak sekolah, dan (e) Memberikan usulan dan masukan kepada pihak sekolah.

Berdasarkan kajian literatur, dokumentasi dan hasil wawancara, dapat dijelaskan sebagai berikut : Pola pembinaan karakter siswa SMK Subbanul Wathon ditekankan pada pembentukan budi pekerti mulia (akhlakul karimah). Hal-hal ditemukan peneliti diantaranya: siswa selalu mentaati peraturan SMK dengan sungguh-sungguh, termasuk peraturan pondok. Misalnya ketika persiapan kajian lepas dluhur, santri dengan tertib antri di depan masjid.

Hal-hal yang menjadi ciri karakter siswa SMK Subbanul Wathon adalah kemandirian dan kesederhanaan. Dua ciri karakteristik tersebut sebagai icon siswa. Karena siswa SMK Subbanul wathon otomatis sebagai santri Pondok Pesantren API Tegalrejo Magelang. Adapun faktor-faktor yang mempengaruhi pola pembinaan siswa SMK Subbanul Wathon diantaranya: latar belakang sosial siswa dan kebiasaan- kebiasaan siswa saat berada diluar lingkungan pondok. 


\section{SIMPULAN}

Berdasarkan hasil kajian dan temuan dilapangan dapat disimpulkan sebagai berikut: (a) Pola pembinaan karakter siswa SMK Subbanul Wathon berbasis pada akhlakul karimah yang berciri pada kemandirian dan kesederhanaan. Hal tersebut menjadi watak, jiwa siswa (santri) SMK Subbanul Wathon, dalam mengarungi kehidupan masyarakat. Integrasi pendidikan ala pondok pesantren Salaf, fasilitas dan manajemen yang cukup moderen.Sedangkan faktor-faktor yang mempengaruhi pola pembinaan siswa SMK Subbanul Wathon diantaranya: latar belakang sosial siswa dan kebiasaan- kebiasaan siswa saat berada diluar lingkungan pondok.

Perlu dilakukan penelitian lanjutan terkait manajemen, penjaminan mutu pada SMK Subbanul Wathon.

\section{DAFTAR RUJUKAN}

(2015). Development Character Education. Diakses melalui www.urbanext.illinois.edu pada 4 November 2017.

. (2016). Character education for kids. Diakses melalui laman http://www.indianchild.com/character/ character_education_index.htm pada 11 Desember 2017.

. (2016). Character Education. Diakses melalui

laman http://eduscapes.com/sessions/graphic/ dynamic.html pada 12 Desember 2017.

Ary Kristiyani. (2014). Model Penalaran Penulisan Artikel Ilmiah Mahasiswa Jurusan PBSI FBS UNY. Jurnal DIKSI vol 2. 22.

Elkin, D \& Sweet, F. (2004). How to Do Character Education. Diakses melalui http://www.goodcharacter.com/Article_ 4.html pada 6 November 2017.

Lickona. (1991). Educating For Character. Diakses melalui laman http://www.goodcharacter.com/Article_ 4.html pada 10 November 2017.

Pemerintah Republik Indonesia. (2003). Undang-Undang No 20 Tahun 2003 tentang Sistem Pendidikan Nasional.

Pemerintah Republik Indonesia. (2005). Peraturan Pemerintah No 19 Tahun 2005 tentang Standar Nasional Pendidikan.

Tutuk Ningsih. (2015). Pengembangan Alat Permainan Edukatif (APE) "Kartu Baca Ngaji Asyik” Sebagai Media Belajar Bagi Anak Usia Dini di TK Aisyiyah Kec. Sokaraja Kab. Banyumas. Laporan Penelitian IAIN Purwokerto, Purwokerto.

Wikipedia. (2017). Character Education melalui laman https://en.wikipedia.org/wiki/Character _education pada 8 November 2017.

Winarno Narmoatmojo. (2015). Pendidikan Kewarganegaraan untuk perguruaan. Yogyakarta: Ombak. 